\title{
GRUPO INTERDISCIPLINAR DE ESTUDOS SOBRE FUTEBOL
}

\author{
Paulo Miranda Favero* \\ Melina Nóbrega Miranda** \\ Fernando José Lourenço Filho***
}

\section{RESUMO:}

Este artigo tem por objetivo apresentar, a partir do processo de formação e de desenvolvimento do Grupo Interdisciplinar de Estudos sobre Futebol na Universidade de São Paulo ao longo do $1^{\circ}$ semestre de 2006, uma breve exposição teórica elaborada com base nas explanações e debates realizados nas reuniões do Grupo, destacando não somente a importância e a pertinência de estudar o futebol, como as dificuldades de abordar esse tema nas diferentes áreas do conhecimento científico. Pretende-se ainda tecer alguns comentários sobre a organização e as atividades do Grupo, marcado por diferentes abordagens teórico-metodológicas decorrentes da sua composição interdisciplinar.

\section{PALAVRAS-CHAVE:}

Futebol; Grupo de Estudos; Interdisciplinaridade; Relato de experiência.

\section{ABSTRACT:}

This article aims to present, from the process of creation and development of the Interdisciplinary Group of Studies about Soccer Game at the São Paulo University throughout the first semester of 2006, a brief theoretical exposition about soccer based on the analyzes carried out during the Group meetings, emphasizing not only the importance of studying soccer, but also the difficulties of dealing with this subject in different areas of the scientific knowledge.

It also intended to introduce some comments about the organization and the main activities of the Group, which is characterized by diverse theoretical and methodological approaches resulting from its multidisciplinary composition.

\section{KEY WORDS:}

Soccer; Group of Studies; Interdisciplinary; Experience Report.

\section{Introdução}

No segundo semestre de 2005, no departamento de História da Faculdade de Filosofia, Letras e Ciências Humanas da Universidade de São Paulo, foi ministrada, no curso de Pós-Graduação em História Social, em sua terceira edição, a disciplina "História Sociocultural do Futebol", pelos Professores Doutores Flávio de Campos e Hilário Franco Júnior. Na ocasião, reuniram-se alunos de diversas áreas do conhecimento, com diferentes abordagens teórico-conceituais sobre o futebol. $\mathrm{Na}$ avaliação final do curso, surgiu a idéia de constituir um Grupo Interdisciplinar de Estudos sobre Futebol $(G I E F)^{1}$, para que pesquisadores, estudantes e interessados continuassem a debater e descobrir novas perspectivas analíticas para estudar o Futebol.

O grupo iniciou seus trabalhos em março de 2006 e, embora esteja em processo de consolidação, já desenvolveu várias frentes de

*Mestrando em Geografia pelo Departamento de Geografia da FFLCH/USP.

**Mestranda em História Social pelo Departamento de História da FFLCH/USP.

***Mestrando em História Social pelo Departamento de História da FFLCH/USP.

E-mail para contato com o grupo: paulofavero2003@yahoo.com.br 
trabalho, a destacar: participação em Seminários e Congressos e organização de eventos similares; realização de entrevistas com profissionais da área futebolística e pesquisadores interessados no tema, desenvolvimento de pesquisas acadêmicas em algumas das principais Universidades do Estado de São Paulo, fortalecendo a possível criação de núcleos de pesquisa nestas Universidades; criação de um grupo virtual para discussões e sugestões bibliográficas; produção de artigos sobre as atividades do grupo.

Apesar da diversidade teóricometodológica decorrente das diferentes linhas de estudos e diversas áreas de formação dos componentes do grupo, uma questão era fundamental para todos: a relevância de estudar o futebol como um elemento cultural abrangente que, quando analisado, nos permite compreender amplamente a sociedade brasileira. Longe de nos fundamentarmos em teorias que vêem o Futebol apenas como instrumento ideológico ("futebol como ópio do povo" ou "fenômeno da indústria cultural"), o vislumbramos como um fenômeno social total, que não só simboliza a sociedade em que se encontra, como se soma a ela e, através da mimesis corporal e coletiva da orquestração social, age como elemento construtor da mesma (BOURDIEU, 1990).

Somente de modo abrangente seria possível compreender como inúmeras questões fundamentais à sociedade brasileira, em vários níveis e dimensões questões econômicas, políticas e sociais, ligadas à modernidade, identidade nacional, racismo, mestiçagem, diferentes formas de sociabilidade, reconhecimento e merecimento social - estão presentes na esfera futebolística como construtoras desse esporte (e não somente como reflexo cultural), ao mesmo tempo em que o próprio futebol interage como elemento dinâmico da cultura.

\section{Linha de trabalho}

A interdisciplinaridade e a diversidade de linhas de pesquisa presentes no grupo se traduziram em questões orientadoras para os trabalhos: Para além da premissa de que o futebol é fenômeno social total, o que mais poderia haver de comum entre os participantes de modo a caracterizar um grupo e não uma mera soma de interesses? $\mathrm{E}$, ao mesmo tempo, como selecionar e organizar leituras que pudessem também contemplar essa diversidade de interesses? Para responder a essas questões, aparentemente contraditórias, mas na verdade complementares, definimos duas principais linhas de atuação: 1)Traçamos um panorama cronológico das principais discussões acerca do futebol dentro e fora do país. A seleção de textos foi orientada a partir da leitura do texto de Toledo (2001) e buscou contemplar uma variedade de gêneros textuais e análises sobre o tema, produzidos em períodos considerados marcantes no desenvolvimento do esporte. Assim, considerando o período de introdução do futebol no Brasil, destacamos as crônicas de Lima Barreto, e alguns ensaios sobre elas, para discutir o impacto sócio-cultural da chegada do esporte nas grandes cidades brasileiras. A profissionalização e as discussões sobre a mestiçagem e o racismo no futebol, nas décadas de 30 e 40, foram contempladas com os textos de Gilberto Freyre e Mario Filho no livro $O$ negro no futebol brasileiro. Para estudar as representações acerca do futebol na década de 50, selecionamos crônicas de Nelson Rodrigues e texto de Anatol Rosenfeld. As décadas de 80 e 90 foram, de uma maneira geral, palcos para algumas discussões históricas, sociológicas, geográficas e antropológicas; no caso dessa última, analisadas à luz de textos de Arlei Damo, Luiz Henrique de Toledo, José Paulo Florenzano, entre outros. Nesse período, destacam-se as pesquisas sobre Torcidas Organizadas de Futebol; 2)Elegemos conceitos e temas fundamentais com os quais todos os representantes do grupo lidam direta ou indiretamente em suas pesquisas individuais. 
Com a finalidade de estudar o futebol como fenômeno social total, produto e produtor da sociedade em que está inserido, realizaremos uma breve exposição teórica baseada em alguns intelectuais examinados durante as reuniões do Grupo Interdisciplinar de Estudos sobre Futebol. Destacamos, inicialmente, os seguintes temas: corpo, técnicas corporais, esporte e modernidade; crônicas/imprensa e identidade nacional; racismo e o elogio da mestiçagem; dom, forma-representação, cotidiano e formas de sociabilidade.

\section{Relação Corpo, Técnicas Corporais, Esporte e Modernidade}

Trabalhando com o conceito de "homem total", o antropólogo Marcel Mauss (2003) teorizou que as "técnicas do corpo" são construídas nas especificidades mecânica e física, anatômica e fisiológica, psicológica e sociológica, o que explicaria não somente a preferência de determinado esporte em uma dada sociedade, como também o modo como ele seria praticado nela. Tais "técnicas corporais" teriam como base instrumental o próprio corpo e, por serem eficazes para aquela sociedade, seriam transmitidas pela tradição oral, basicamente, através da qual a cultura popular de fato se mantém.

Portanto, técnicas do corpo, para Mauss (2003, p. 401), são "as maneiras pelas quais os homens sabem servir-se de seu corpo". O drible, por exemplo, só teria sido valorizado porque existe um repertório corporal na sociedade brasileira capaz de fomentar jogadores como Leônidas da Silva em suas bicicletas, Roberto Rivelino em seus elásticos ou Robinho em suas pedaladas, como sugeriu Gilberto Freyre.

O futebol nos permite discutir a relação entre corpo e modernidade porque seu aparecimento se dá no contexto de construção do mundo moderno que produz novas técnicas e práticas corporais. $\mathrm{Na}$ modernidade, as técnicas corporais estão diretamente relacionadas ao desenvolvimento tecnológico e científico e são intensamente percebidas no universo das relações de trabalho. Assim, desde a Revolução Industrial, a máquina passou a ser parâmetro para a avaliação do rendimento profissional ou mesmo da beleza, para as pessoas de todas as classes sociais, alterando e criando novas técnicas corporais, como fruto do impacto desse desenvolvimento (SANT'ANNA, 1995).

Por outro lado, podemos afirmar que essas técnicas estão relacionadas com o "processo civilizador", descrito por Elias (1992), na parlamentarização dos regimes políticos no mundo ocidental no século XIX. Segundo esse autor, os jogos acompanharam as transformações sociais de seus respectivos países. Analisando a transformação dos territórios medievais em Estados Nacionais, Elias destaca os jogos como um dos fatores (entre a etiqueta e outros fatores comportamentais) integrantes dessa transformação, que através de um "processo civilizador" perpassou todos os níveis sócio-culturais. À medida que houve uma centralização e um monopólio da força física com o desenvolvimento de um maior controle social (característica do "processo civilizador"), as atividades ficaram menos violentas e mais reguladas - dando início aos "desportos" em seu sentido moderno, Elias (1992).

$\mathrm{Na}$ Inglaterra, por exemplo, as técnicas corporais foram incorporadas aos currículos escolares como um saber e um exercício, porque serviam ao adestramento e contenção dos impulsos violentos dos jovens oriundos da nobreza. O esporte pressupõe a igualdade de condições entre os competidores pela existência de regras universais conhecidas e legitimadas por todos.

Portanto, teria sido com os desportos que as competições integraram um conjunto de regras que assegurou o equilíbrio entre a possível obtenção de uma elevada tensão na luta e uma razoável proteção contra ferimentos físicos. Essas noções de normas e regras não teriam sido feitas separadamente dos homens, para depois regê-los em sociedade. Elas se construíram baseadas nas idéias de justiça, juntamente com o comportamento do homem 
em sociedade - assim como o seu comportamento se construiria baseado nelas, através de uma relação dialética.

Assim, além de revelá-la, o futebol faz parte da modernidade, pois é elemento dinâmico da cultura: constrói identidades, serve como prática cotidiana de lazer ou como profissão, altera a paisagem urbana nas sociedades contemporâneas etc.

\section{As Crônicas, a Imprensa e a Identidade Nacional}

A construção de uma identidade nacional acerca do futebol utiliza-se de alguns meios para que o esporte bretão possa, de um certo modo, interagir com a sociedade a ponto de torná-lo tradição. Seria esse o caso das crônicas esportivas que, desde as primeiras décadas do século $X X$, permeiam as páginas dos jornais. Sendo "contra" ou "a favor" do football, elas criam uma enorme gama de possibilidades do "ser" brasileiro.

No Brasil, a crônica expandiu-se principalmente no Rio de Janeiro, dada a enorme concentração de escritores na então capital federal. Segundo Costa (2001, p. 20), o uso da linguagem radiofônica esportiva foi incorporado pela imprensa escrita, servindo como base para a comunicação. Essas primeiras publicações surgiram em forma de crônicas, de fácil leitura, ganhando espaço no cenário da época, já que apresentam como principais características "trazer uma gama imensa de temas cotidianos colados ao seu tempo, bem como evidenciar tais fatos e acontecimentos no seu processo de efervescência e criação cultural" (TOLEDO apud CANDIDO, 1996, p. 39). Pouco tempo depois, este gênero cairia nas graças dos escritores brasileiros.

Nas primeiras décadas do século $X X, 0$ Brasil passava por transformações políticas, culturais e sociais, relacionadas ao processo de modernização. Vivíamos em um contraste: por um lado, a estabilidade, com a política do cafécom-leite e, por outro, uma série de revoltas que aconteciam em todo o país. Alguns escritores, como é o caso de Lima Barreto, eram avessos ao esporte que chegara da Inglaterra e que, dia após dia, ganhava mais espaço no cotidiano brasileiro. Talvez essa sua aversão possa ser explicada pelo próprio contexto de nosso país à época. O escritor vivia intensamente as mudanças daquele período, estando atento a dois fatos em particular: o processo de institucionalização do futebol e a consolidação do Estado e da nação brasileira. Assim, sendo defensor do crescimento das camadas populares em nosso país, era crítico ao "esporte bretão", por acreditar tratar-se de um esporte "de elite"; identificava nele fatores de desunião e o caracterizava como uma, entre outras, forma de perpetuação da dominação exercida no regime escravista.

O escritor, em uma de suas crônicas, afirma: "não acredito que um jogo de bola, e, sobretudo jogado com os pés, seja capaz de inspirar paixões e ódios. Mas, não senhor! A cousa era a sério e o narrador da partida, mais adiante já falava em armas" (RESENDE \& VALENÇA apud BARRETO, 2004, p. 372). Sua repugnância foi tamanha que fundou, em 1919, a "Liga contra o Foot-ball", com artigos que exaltavam os prejuízos que o esporte poderia causar aos indivíduos. O escritor "acreditava que somente jogadores ou adeptos de outros divertimentos brutais" é que se deleitariam com essas "seções esportivas" (COSTA, 2001, p. 15). Ledo engano.

Ao contrário do que Lima Barreto pensara fazer em suas crônicas contra o futebol - ou seja, banir o esporte de nossa sociedade -, suas críticas, a longo prazo e até hoje, acabaram por evidenciar a significativa popularização do futebol no país. "E, mais ainda, o futebol de sua época [...] já consistia em uma das possíveis configurações culturais por onde se poderia 'ler' o Brasil do período" (TOLEDO, 1996, p. 49).

A popularização do futebol fez com que o jornalismo esportivo e, com ele, as crônicas, também ficassem em evidência: "A invenção do jornalismo esportivo é, assim, paralela à invenção do futebol profissional; são dois 
aspectos de uma mesma invenção [...] De uma certa maneira, é o jornal que cria a demanda e que produz o evento, quer dizer, torna-o visível como fenômeno político ou nacional" (LEITE LOPES, 1994, p. 82).

De modo significativo, outro escritor brasileiro contribuiu para que essa identidade se expandisse através de uma imprensa especializada. Mario Filho - irmão de Nelson Rodrigues - foi o responsável por idéias inovadoras tanto com relação às crônicas e seu profissionalismo, como também à incorporação das massas ao futebol. É ele quem antecipa a produção de notícias sobre futebol, desde seus treinos ou momentos que antecedem ao jogo, entrevistando jogadores e fabricando eventos. Renova, assim, o jornalismo esportivo, já que antes, os "repórteres esportivos ocupavam a posição mais baixa da hierarquia dos jornalistas, os que cobriam futebol escorando seus pobres salários com as refeições que os clubes lhes ofereciam nos dias de treino" (TOLEDO apud LEITE LOPES, 1994, p.68).

Entusiasta e crítico do futebol, talvez o maior até hoje, o jornalista Nelson Rodrigues ajudou na construção da identidade e do imaginário brasileiro, por meio do futebol. $\mathrm{Na}$ crônica intitulada Pátria em chuteiras, afirma: "para nós, o que é o escrete? Digamos - é a pátria em calções e chuteiras, a dor de rútilas botinadas, em todas as direções. O escrete representa os nossos defeitos e as nossas virtudes" (CASTRO, 1994, p. 42). É ele também que nos revela que o futebol pode ser arte, prova disto são suas crônicas sobre Mané Garrincha e Pelé. Aliás, Rodrigues, antes mesmo da conquista da primeira taça Jules Rimet, chamou Pelé de "Rei".

Em sua crônica A Poesia do futebol, Rodrigues indaga o que o torcedor procura numa partida. Esse trecho demonstra a importância de a crônica esportiva se comportar como meio de produção cultural e de identidades. "A meu ver o que nós procuramos nos clássicos e nas peladas é a poesia. A coisa pode soar falsa, mas insisto. As coisas só nos atraem por sua possibilidade poética" (RODRIGUES apud SUSSEKIND, 1997, p. 71). Nessa perspectiva, a crônica esportiva se comportaria como mediadora entre o fato, no caso o jogo, já narrado, e os espectadores, (re)contando-o para que os espectadores o registrem como parte integrante do seu cotidiano, convertendo o passado em presente.

O jogo de futebol acaba por ganhar um status de "função social", a partir de um estabelecimento de relações sociais (entre torcedores e os jogadores) e mudanças de uma certa ordem na sociedade. Manhães (2004) acredita que o fato corresponde às vozes de um sujeito social determinado - o povo - e sua produção discursiva - o jogo - que expressa sua nacionalidade: a cultura popular. Essa questão cultural torna-se evidente a partir do momento em que se encontra um sentido para tal fenômeno, uma vez que a própria cultura nasce onde os homens produzem a base de sua vida.

Se o futebol, como nos afirma DaMatta (1982), permite-nos também descobrir nossa "alma" e nosso "coração" de modo positivo, a crônica deveria ser usada em sua essência, como um intérprete da realidade, para levar ao seu leitor signos que pudessem, efetivamente, fazer de um 'simples' jogo de futebol, fonte de entendimento do seu próprio 'eu'.

\section{Racismo e Elogio à mestiçagem}

Partindo da idéia do futebol como o esporte que representaria a identidade nacional brasileira (graças a processos historicamente constituídos), Mario Filho (2003), numa abordagem próxima à de Elias, pensou o esporte como civilizador moral da sociedade e realizou um estudo sócio-psicológico da sociedade brasileira via futebol. Analisando a inserção dos negros e mestiços na prática futebolística, o autor vislumbrou a ascensão desses grupos na sociedade brasileira concomitantemente ao engrandecimento do próprio futebol, graças à contribuição técnica 
que os negros e mestiços trouxeram para esse esporte.

Dentre os muitos temas que o futebol engloba, a "dupla" racismo e elogio à mestiçagem é, senão uma das mais recorrentes, uma das primeiras discussões trazidas à baila de maneira mais significativa por aqueles que perceberam nesta prática lúdica uma importante janela através da qual fosse possível compreender alguns aspectos importantes da sociedade brasileira. Entre os autores que trabalham essa temática, exceção feita a Gilberto Freyre, o racismo enquanto forma de preconceito contra negros e mestiços aparece como algo intrínseco ao futebol e, em conseqüência, à sociedade brasileira. Por outro lado, já havia vozes que questionavam o elogio à mestiçagem e a apologia de que o mesmo esporte seria a tradução mais clara, em termos práticos, de uma "hipotética" democracia racial vivida em nosso país.

Mario Filho (2003) procura demonstrar, através de uma história do desenvolvimento do futebol desde seus primórdios até a Copa do Mundo de 1962, como essa prática foi aos poucos se transformando, passando de algo restrito às elites a uma verdadeira manifestação popular, e mais importante ainda, transformando-se em uma ferramenta de ascensão social, principalmente para negros e mestiços, que têm como base fundamental para isso a profissionalização do futebol. O autor mostra, através das biografias de Friedenreich, Fausto, Leônidas, Barbosa, Pelé, Didi e Garrincha, dentre outros jogadores, como negros e mestiços conquistaram arduamente, ao longo dos anos, seu espaço dentro do futebol. Rosenfeld (1993) questiona a análise de Mario Filho (2003), pois considera que se, por um lado, temos no futebol a possibilidade de uma certa ascensão social, por outro, temos a percepção que esta mesma mobilidade social é restrita em termos financeiros, e não é acompanhada, na mesma medida, de um reconhecimento social. Faltaria, na obra de Mario Filho, uma perspectiva de maior alcance, principalmente, para as questões do trabalho, sempre visto como algo depreciativo pelas nossas elites, e da própria mobilidade social na história de nossa sociedade.

No centro deste debate surge a questão do assim chamado Elogio à Mestiçagem, corrente fortemente defendida por Mario Filho e Freyre (2003). Esses autores alegam que as razões de nosso sucesso futebolístico residiriam justamente em nossa mestiçagem racial. A confluência de elementos europeus, ameríndios e africanos resultaria em um maior jogo de cintura e em um caráter muito mais dionisíaco e festivo, do que apolíneo, mais "sério" e "clássico", por conseqüência, mais próximo do europeu. Em outras palavras, essa concepção poderia nos induzir ao erro de acreditar que o jeito brasileiro de jogar teria suas raízes em laços raciais e, não culturais, idéia altamente discutível. Ambos os autores ressaltam que o aspecto cultural influencia o nosso estilo, seja ao perceber alguma semelhança com a capoeira ou o samba na "ginga" do jogador, seja ao ressaltar a formação familiar e o amor precoce pela bola como fatores preponderantes no sucesso de Pelé. O que se deve apreender desse elogio da mestiçagem é o contexto histórico de tais idéias e com quais outros pensamentos elas estavam dialogando. A idéia do elogio surge como modo de combater o racismo em uma sociedade com um forte passado escravocrata recente (naquele contexto histórico), afirmando e valorizando as contribuições tanto de ameríndios quanto de africanos na formação da cultura brasileira, que sistematicamente colocados, ao longo dos anos, à margem da sociedade, agora se viam como protagonistas em uma prática lúdica, o futebol, pensada como uma nova forma definidora de uma certa identidade nacional.

\section{O dom e a forma-representação}

Esse debate em torno da idéia de que os negros possuem uma predisposição para o futebol, muito difundida no cenário futebolístico 
e literário sobre o tema, já foi dado como encerrado por inúmeros trabalhos acadêmicos, porém ainda faz parte do senso comum do futebol. Alguém já deve ter escutado a frase: "o cara joga bem porque é negro". Nessa perspectiva, utiliza-se a categoria "raça" para justificar um aprendizado que estaria, aparentemente, mais intimamente vinculado à cultura de um país. É mais provável que o indivíduo jogue bem não porque é negro, mas sim pelo fato de ter participado de uma série de experiências em termos futebolísticos, entre elas a da exclusão social brasileira, que, por razões sócio-históricas, atinge parte da população negra. Essa linha de raciocínio explicaria, em parte, o porquê de muitos jogadores profissionais serem oriundos de espaços mais carentes, como periferias, favelas e bairros suburbanos.

Entretanto, para além dessa explicação cultural, é comum atribuir ao jogador de futebol o estigma de que ele seja um predestinado, ou seja, a pessoa certa, na hora certa, para resolver os problemas que estão à sua frente. No futebol, geralmente o "escolhido" justifica-se por meio da crença de que possui um dom para esse esporte, vinculando suas conquistas à figura de Deus. Dessa forma, reforça-se a idéia de que não precisou aprender a jogar e que seu talento seria uma bênção, ou melhor, uma dádiva divina.

A teoria diz que o dom pode assumir dois significados amplos e complementares: pode ser sinônimo de uma dádiva de Deus ou sinônimo de talento (DAMO, 2005). O dom serviria, por exemplo, para explicar como um atleta chega à seleção brasileira, como em um jogo de meninos uns se destacam mais do que os outros ou como diante de tanta concorrência nas categorias de base, alguns deles conseguem chegar à categoria profissional. Como sustentar que jogam bola porque possuem um dom? Todo o aprendizado não pode ser considerado como um complemento do dom, mas sim como a parte principal de todo processo.
Como destaca Souza (1996), as qualidades dos jogadores brasileiros não podem ser encaradas como características inatas e geneticamente herdadas. O futebol, por integrar e dar sentido a nossa sociedade, é construído culturalmente, e o ensino e desenvolvimento de habilidades durante a infância, nos campos improvisados na rua ou nas escolinhas, são capazes de explicar "o dom do jogador brasileiro para o futebol".

Damo fez um levantamento ${ }^{2}$ da quantidade de horas de treinamento a que os jogadores são submetidos até alcançar o profissionalismo e chegou a um número de aproximadamente 5.650 horas dedicadas ao sonho de ser jogador. Nesse processo, os corpos desses meninos são submetidos a um aprendizado equivalente a um curso de graduação. Não podemos esquecer, porém, que, em termos de horas, eles já haviam praticado futebol antes de entrarem para as categorias de base. Contudo, para além dos que tiveram êxito, é importante questionar o que acontecerá com o grande número de jovens que serão expelidos do processo de formação de jogador, já que não possuem qualquer perspectiva de re-inserção social, pois como diz Damo, "o que se pode fazer com os pés além de jogar bola?" (2005, p. 182).

O estilo de jogo brasileiro estaria vinculado a essa discussão do dom. Contestando a visão de que o estilo é algo "natural" e que não pode ser aprendido, Toledo (2002) classifica em três grupos os atores presentes no cenário futebolístico ${ }^{3}$ : os profissionais, composto pelos jogadores, técnicos, comissão técnica, árbitros etc; os especialistas, nesse caso, os profissionais de mídia e imprensa esportiva; e, por fim, os torcedores, os amantes do futebol de uma maneira geral. Para o autor, há um embate constante entre esses grupos a respeito da prática futebolística: os torcedores querem gols e o máximo de aprimoramento das performances; os especialistas tentam desvendar os segredos sobre os times para transformá-los em notícia; e os profissionais 
buscam uma forma ou padrão de jogo que, bem sucedida, atingirá no plano simbólico, as representações do jogar.

A forma (ou padrão de jogo) seria nada mais do que o sistema tático da equipe e sua distribuição dentro de campo. A representação seria a interpretação (logo, acontece no plano simbólico) da atuação da equipe, amparada pelo sistema tático que a delineia. O estilo, portanto, seria o resultado da soma de interpretações e diálogos diferentes de uma mesma coisa, ou seja, da maneira de jogar. Assim, os torcedores querem uma determinada forma de jogar, que seria estabelecida pela relação entre técnico, comissão técnica e características dos jogadores que compõem o elenco durante os treinamentos. Os especialistas que analisam a prática, especialmente no momento do jogo formal, realimentariam o imaginário do torcedor a respeito do que é o estilo de jogo de um determinado time ou da seleção brasileira.

Portanto, o estilo de jogo está em constante diálogo e pertence a um ciclo que realimentaria constantemente a discussão sobre as maneiras de se jogar futebol. O que torna o estilo de jogo importante para o entendermos como um fenômeno cultural seria a interação do plano simbólico com a prática de futebol. Sem essa interação entre os elementos citados não haveria motivo para falarmos em estilo de jogo.

\section{Próximos desafios e considerações finais}

A experiência do Grupo Interdisciplinar de Estudos sobre Futebol tem sido profundamente enriquecedora, ao colocar em debate a produção acadêmica sobre o tema, devido à considerável ampliação dos estudos sobre o esporte no campo das Ciências Humanas, em especial, realizada pela Sociologia e Antropologia. A publicação desse artigo visa elucidar não somente a importância e a pertinência de estudar o futebol, como revelar as dificuldades encontradas para vislumbrá-lo nas diferentes áreas do conhecimento científico e traçar novos desafios para o ano de 2007.
Entre esses desafios, destacamos o debate dos conceitos formulados por Huizinga (2005), que trabalhou a noção de "jogo" no singular, tratando-o como uma totalidade anterior à própria cultura, cuja essência seria o divertimento e seu significado estaria centrado em si mesmo e para seus jogadores. Seria possível haver autonomia entre o jogo e as relações sociais, como conceituou Huizinga? Essas relações não trariam significações específicas dependendo do contexto social que se encontra a modalidade lúdica? Não haveria uma relação mútua entre jogo e sociedade? Não devemos pensar em "jogos" diferentes entre si, de sociedade para sociedade?

Frente à discussão que Huizinga faz do conceito de "jogo", vale a pena retomar os trabalhos de Roberto DaMatta (1982) que, ao pensar na importância dos jogos nas diferentes sociedades, introduziu uma nova categoria conceitual para a noção de jogo: a de drama. Este seria o elemento básico da ritualização, enquanto que o rito constituiria o meio através do qual uma sociedade entenderia a si própria, e o esporte como drama expressaria a identidade nacional, seus problemas, percepções, elaborações intelectuais e emocionais, e seus sentimentos concretamente sentidos e vividos.

Portanto muitos dos estudos produzidos nas décadas de 80 e 90 beberam da "fonte" de DaMatta e de sua abordagem do futebol enquanto drama, enfocando o "esporte nacional" como articulador de várias esferas de sociabilidade, identidades culturais, de práticas, discursos, hierarquias, crenças, etc. Ao colocar em debate as pesquisas mais recentes, produzidas em diversas esferas das ciências humanas, problematizamos também quase um século de produção textual sobre o Futebol no Brasil. Porém, independente das periodizações históricas, o importante é saber que esse fenômeno social foi diariamente "vivido, reproduzido e reinventado" no século XX. 


\section{Notas}

1 O GIEF é formado pelas seguintes áreas: Antropologia, Educação Física, Geografia, História e Jornalismo.

2 Uma rica experiência etnográfica feita, principalmente no Sport Club Internacional, de Porto Alegre, e no Olympique Marseille, na França.
3 Toledo analisa uma pluralidade de contextos e atores envolvidos com o campo futebolístico, tomando como significativos espaços rituais e cotidianos de construção de representações: cursos para treinadores, botecos e programas esportivos de televisão (2002, p. 15-18).

\section{Bilbiografia}

BOURDIEU, Pierre. Programa para uma sociologia do esporte. IN: BOURDIEU, Pierre. Coisas ditas. São Paulo: Ed. Brasiliense, 1990.

CASTRO, Ruy. À Sombra das Chuteiras Imortais. São Paulo: Companhia das Letras, 1993.

A Pátria em chuteiras. São Paulo: Companhia das Letras, 1994.

COSTA, Andréia C. Barros. Bate-bola com a crônica: O futebol, o jornalismo e a literatura brasileira. 2001. 88f. Tese (Mestrado em Comunicação Social) - Faculdade de Comunicação de Juiz de Fora, Juiz de Fora, 2001.

DAMATTA, Roberto (Org.). Esporte e sociedade brasileira. IN: DAMATTA, Roberto. Universo do Futebol. Rio de Janeiro: Pinakotheke, 1982.

DAMO, Arlei S. Do dom à profissão. 2005. 435f. Tese (Doutorado em Antropologia Social) - Instituto de Filosofia e Ciências Humanas, Universidade Federal do Rio Grande do Sul, Rio Grande do Sul, 2005.

ELIAS, Norbert. Ensaio sobre o desporto e a violência. IN: ELIAS, Norbert; DUNNING, Eric. A busca da excitação. Lisboa: Difel, 1992.

FREYRE, Gilberto. Prefácio. In: RODRIGUES FILHO, Mario. O negro no futebol brasileiro. Rio de Janeiro: Mauad, 2003.
HUIZINGA, Johan. Homo Ludens. O jogo como elemento da cultura. São Paulo: Perspectiva, 2005.

LEITE LOPES, José S. A vitória do futebol que incorporou a pelada. Revista USP, Dossiê Futebol, São Paulo, n.22, p. 64-83, 1994.

MANHÃES, Eduardo. João Sem Medo - Futebol Arte e Identidade. São Paulo: Pontes, 2004.

MAUSS, Marcel. Sociologia e antropologia. São Paulo: Cosac \& Naify, 2003.

RESENDE, Beatriz \& VALENÇA, Rachel. Toda Crônica, Lima Barreto. Rio de Janeiro: Agir, 2004.

RODRIGUES FILHO, Mario. O negro no futebol brasileiro. Rio de Janeiro: Mauad, 2003.

São Paulo: Estação Liberdade, 1995.

SOUZA, Marcos A. de. Gênero e raça: a nação construída pelo futebol brasileiro. Cadernos Pagu, Campinas, n. 6-7, p. 109-152, 1996.

SUSSEKIND, Hélio Carlos. Futebol em dois tempos. Rio de Janeiro: Relume - Dumará, 1996

TOLEDO, Luiz H. de. Contribuições ao estudo da crônica esportiva 1: a "contracrônica" esportiva de Lima Barreto. Pesquisa de Campo. Rio de Janeiro, n. 3-4, p. 37-51, 1996. 
Futebol e teoria social: aspectos da produção científica brasileira (1982-2002). BIB - Revista Brasileira de Informação Bibliográfica em Ciências Sociais, São Paulo, n. 52, p. 133165, 2001.
. Lógicas no futebol. São Paulo: Hucitec, Fapesp, 2002.

Trabalho enviado em agosto de 2007

Trabalho aceito em setembro de 2007 